\title{
A Study of Congenital Malformations amongst Hospital Deliveries, Gauhati Medical College and Hospital, Guwhati
}

\author{
${ }^{1}$ Aratideka, ${ }^{2}$ Niru Prabha Saharia, ${ }^{3}$ Ranjit Timung, ${ }^{4}$ Vivekananda MS \\ ${ }^{1}$ Professor Of Paediatrics, Gauhati Medical College And Hospital, India \\ ${ }^{2}$ Associate Professor Of Paediatrics, Gauhati Medical College And Hospital, India. \\ ${ }^{3}$ ajunior Resident Of Paediatrics, Gauhati Medical College And Hospital, India. \\ ${ }^{4}$ ajunior Resident Of Paediatrics, Gauhati Medical College And Hospital, India.
}

\begin{abstract}
:
Introduction:Structural and functional abnormality can be major or minor abnormality constituting congenital malformation.

Method:Prospective study after approval from the hospital ethical committee was conducted from 1 July 2014 to $30^{\text {th }}$ June 2015

Result:A total of 130 new born were delivered with single or multiple congenital anomalies from 130 mothers. In the study the incidence of congenital malformation was $0.81 \%$. Of which male babies with malformation was high. Musculoskeletal anomaly was the most common in which CTEV was the most common anomaly. Most of the malformed babies were low birth weight and they belong to low socioeconomic families. The survival rates of the malformed babies were high in this study.

Conclusion:The knowledge about congenital malformation helps inits prevention by early Medical termination of uncontrollable severe malformation. The life threatening congenital malformation must be identified by thorough clinical examination and other investigations because early detection and surgical correction of these infants offer the best chance of survival.
\end{abstract}

Keywords: Congenital malformations, CTEV, Gauhati medical college.

\section{Introduction}

Birth defects can be defined as structural or functional abnormalities, including metabolic disorders, which are present at birth. The term congenital disorder is considered to have the same definition.

WHO estimates that 2,60,000 deaths are caused by congenital anomalies world wide ${ }^{1}$. In India, it has been observed that they constitute $22 \%$ of all early neonatal deaths.

Congenital anomalies can be divided into major and minor. Major malformations are structural abnormalities that have medical and cosmetic consequences. Minor malformations are anomalies with no medical or cosmetic significance. Most of the minor abnormalities are limited to the head and neck region. Infants with three or more minor abnormalities are at a high risk for having major malformation or syndrome. ${ }^{2}$ The common causes of congenital anomalies can be grouped into genetic, environmental and multifactorial Genetic causes include chromosomal aberrations (10-15\%) and mendelian inheritance (2-10\%).

Environmental causes can be divided into maternal/placental infections (2-3\%), Maternaldisease states (6-8\%), Drugs and chemicals $(1 \%)$

Multifactorial causes account for $20-25 \%$ of cases. Multifactorial inheritance refers to the interplay between environmental factors and two or more genes of small effect. This is the most common genetic cause of congenital malformations.

An important way of preventing congenital anomalies is by intervening with these environmental influences, for instance preventing maternal infections or drug intake during pregnancy can avert the occurrences of many types of anomalies. Another example can be seen by the mere intake of folic acid during pregnancy which can dramatically reduce the incidence of neural tube defects ${ }^{3}$.

Studies have shown that majority (94\%) of all the congenital malformations occur in middle and low income groups where mothers are exposed to factors of low socioeconomic status such as macro and micronutrient deficiencies, infections and other factors.

Human development begins in the intrauterine life as soon as fertilization occurs. Between the embryonic and fetal period, an assault usually results in teratogenic effects.

\section{Aims and Objectives}

1] To find out the incidence of congenital malformations within 3 days of birth, delivered in department of Obstetrics and Gynaecology, Gauhati Medical College and Hospital, Guwahati.

2] To Study the Pattern of Congenital Malformations 
3] Early Diagnosis of Life Threatening Malformation.

4] To Study the Possible Etiological Factors.

\section{Materials and Method}

The present study was conducted in the Department of Obstetrics and Gynecology, Neonatal Intensive Care Unit, Gauhati Medical College and Hospital, Guwahati, to find out the frequency and pattern of congenital malformations. The study was done prospectively for a period of one year from 1 July 2014 to $30^{\text {th }}$ June 2015 .

3.1 Inclusion Criteria: All the babies born during the study period both live and still born were included.

3.2 Exclusion criteria: All abortions were excluded and parents who refused to give consent for the study.

During this one year study period, 15958 consecutively born babies history was taken and were examined within the first 3 days of delivery to find out congenital malformations. A thorough physical examination was done as soon as possible, usually before 3 days of birth. Detailed anthropometric measurement was done in all the babies. A feeding tube was taken to check choanal atresia and oesophageal atresia. All the system of the baby i.e musculoskeletal system, central nervous system, respiratory system, gastro intestinal system, genitourinary system, orofacial area including the eye,nose and ear were examined thoroughly to find out presence of congenital anomaly.Investigations were done according to Table 1

The live born babies with congenital malformations those who survived were reexamined at the time of discharge and were followed up.

\section{Results and observation}

Out of 15958 births 92 pairs of twin and 4 sets of triplet was delivered by 15862 women. Thorough maternal history, clinical examinations of new born and necessary laboratory investigations were carried out. A total of 130 new born were delivered with single or multiple congenital anomalies from 130 mothers.

$\begin{array}{lll}\text { Profile of Study Population: } & & \\ >\text { Total Birth } & : & 15958 \\ >\text { Live Birth } & : & 15164 \\ >\text { Still Births } & : & 794 \\ >\text { Twin } & : & 92 \\ >\text { Triplet } & : & 4 \\ >\text { Male } & : & 8104 \\ >\text { Female } & : & 7854 \\ >\text { Baby with malformation (Total ) } & : & 130 \\ >\text { Live birth with malformation } & : & 120 \\ >\text { Still Birth with malformation }: & 10 & \end{array}$

In the study the incidence of congenital malformation was $0.81 \%$ among 15958 new born babies. The incidence of malformed male babies were $78(0.96 \%)$ whereas female babies were $52(0.66 \%)$. Two cases of ambiguous genitalia were included in female sex after confirmation of internal sex organs by ultrasonography. The male to female ratio was $1.5: 1$. There was significant $(\mathrm{p}<0.05)$ difference in malformation between the sexes of newborn.

In the study maximum number of malformation was found in musculoskeletal system 2.63/1000 births, out of which congenital telepesequinovarus (1.37/1000) deformity was commonest.Out of total 15958 deliveries, 130 newborns had single or multiple malformations. A total of 172 types of malformations were found. Most of the malformations were found in musculoskeletal system (24.41\%) followed by central nervous system $(17.44 \%)$ and gastrointestinal system (12.79\%). Eye abnormalities were found in least number of cases (2.33\%), shown in Table 2 and Figure 1.

Majority of malformed babies were in low birth weight $<1.5 \mathrm{~kg}-2(3.2 \%)$ and it was found to be statistically significant. Most of the malformed babies were term - IUGR (3.13\%) followed by pre-term babies $(2.01 \%)$.It was seen that mothers of most of the malformed baby were seen in age group 20-25 years but as compared with same age group the percentage is low $1.06 \%$. With increasing mother's age the malformation is gradually increasing. Most of the mothers with congenital malformation were illiterate. Most of the mother with congenital malformation had no antenatal check-up i.e. 70(53.85\%).According to socioeconomic status by Kuppuswamy classification, upper class malformation was low i.e. 4 (3.08\%) as compared to middle class 30 $(23.08 \%)$ and lower class $96(73.84 \%)$. Table 3shows correlation of antenatal factors with congenital malformation. Out of 130 mothers, $16(12.30 \%)$ had fever during antenatal period followed by $12(9.23 \%)$ cases had PIH and $10(7.69 \%)$ had antepartum hemorrhage .None of the mother had history of exposure to drug, radiation or addiction to alcohol or tobacco. It was also observed that majority of the stillborn infant $(80.00 \%)$ 
had congenital malformations of central nervous system. The incidence of which was quite high when compared to incidence of central nervous system of total malformed births $(17.44 \%)$. It was also found that $2(1.54 \%)$ babies died due to meningocele. 1 case $(0.77 \%)$ of meningocele with TEF, 1 case of Hypoplastic left heart syndrome and 1 case of Hydrocephalus died in first week of life.

\subsection{Congenital malformation in relation to incidence:}

\section{Discussion}

In a period of 1 year from $1^{\text {st }}$ July 2014 to June 2015 a total of 15958 babies were born from 15862 mothers. Out of these 130babies were found to have congenital malformation.

Incidence of congenital malformation in present study was 8.1/1000. The incidence of malformation among live births was $0.79 \%$, where in still birth was $1.26 \%$.

The incidence in our study is comparable to Swain S et.al $1988^{4}(0.9 \%)$. The incidence of the malformation was different in other studies as shown in the Table 4, the difference is due to geographic variation and variation in the community itself.

\subsection{Congenital malformation in relation to sex distribution:}

The male to female ratio was $1.5: 1$. Incidence of congenital malformation was significantly higher in male babies which is similar to the study by Bhat BV et al $1998^{5}$ (1.5:1). Even Dutta V et al 2006 ${ }^{6}$, Hatibaruah A et.al also found higher incidence in male babies.

\subsection{Incidence of Individual Congenital Malformation;}

Central Nervous System: Incidence of CNS malformation was 1.87 per 1000 births, which is the $2^{\text {nd }}$ most commonly involved system in the present study. Our study resembles the study by Dutta $\mathrm{V}^{6}$ et.al $(1.71 / 1000$ births). The difference in the incidence among different studies could be attributed to difference in the study population, study period, geographic location. The commonest malformations in this study were hydrocephalus and meningocele. The frequency of neural tube defect was $0.99 / 1000$ births which was very close to the study by Bhide $\mathrm{P}$ et $\mathrm{al}^{7}$.

Musculoskeletal system: The incidence of congenital malformation of musculoskeletal system was $2.63 / 1000$ births, which is similar to the study by Shah K et $\mathrm{al}^{8} 2013$, Gorpade $\mathrm{N}$ et $\mathrm{al}^{9} 2015$, Grover $\mathrm{N}$ et.al ${ }^{10}$ 2000, Rani S et al $^{11} 2010$. In the present study the commonest system involved was the musculoskeletal system. Study done by Datta V et $\mathrm{al}^{6}$, Bhat BV et al ${ }^{5}$ also found musculoskeletal system to be the most commonly involved. Musculoskeletal system tops the list of most study series because they are externally visible and readily identified at birth.The commonest malformation observed was CTEV.

Gastro intestinal system: Incidence of congenital anomaly in gastrointestinal system was 1.37 per 1000 births. Our study closely resembles the study of SarkarS et al ${ }^{12} 2013$. The commonest malformation was imperforate anus $(0.5 / 1000)$.

Orofacial malformation: Incidence was $0.87 / 1000$ births. Our study closely resembled the study of Swain S et al ${ }^{4} 1994$.

Genitourinary system: The incidence was $1.13 / 1000$ births. Our study closely resembled most of the other Indian studies.

Cardiovascular System: Incidence was $0.88 / 1000$ births. Our study closely resembled the study by Datta V et al 2000 and Hatibaruah A et $\mathrm{al}^{13} 2013$ and differed from other studies due to variations in location, study period, sample size.

Malformation of the eyes accounted to an incidence of $0.25 / 1000$.the most common defect was congenital cataract. Malformation of ears accounted to the incidence of $0.37 / 1000$. The most common defect was microtia. In the study the incidence of syndromic babies were $0.62 / 1000$ all of which were Downs syndrome. Our study closely resembled other study like Bhat BV et al 1998 and Datta V et al ${ }^{5} 2000$. There were 8 cases of hemangioma and 2 cases of pre aural tag. The total incidence of cutaneous malformation was $0.75 / 1000$ births which didn't match with any of the other studies.

Distribution of congenital malformation according to birth weight: congenital malformation were significantly high in birth weight of less than $1.5 \mathrm{~kg}(3.2 \%)$ followed by $1.5-2 \mathrm{~kg}(2.7 \%)$. This was similar to the study by Swain S et $\mathrm{al}^{4} 1994$ and Bhat BV et al ${ }^{5}$. 
Distribution of congenital malformation according to gestational age: maximum number of babies were term - IUGR(3.13\%) followed by pre term babies.(2.01\%) Most of the previous studies like Rani Set $\mathrm{al}^{11}$, SarkarS et $\mathrm{al}^{12}$,Singh K,Krishnamurthy $\mathrm{K}$ et $\mathrm{al}^{14}$ found that increase incidence of congenital malformations in babies delivered preterm and term IUGR.

Distribution of congenital malformation according to maternal age: Maternal age more than 30 had more congenital anomaly in our study. Similar observations was done by Swain et $\mathrm{al}^{4}$, Singh K et al, Krishnamurthy $\mathrm{K}$ et $\mathrm{al}^{14}$.

Relation between congenital malformation and some antenatal factors: In the present study $12.30 \%$ of mothers had history of fever during first trimester. Smith DW et al ${ }^{15} 1978$ established correlation between CNS malformation and maternal hyperthermia. This was again witnessed in our study as well. In our study we could establish a relation between congenital malformation and PIH but this could not be established in any other study. 10 mothers with congenital malformation of their babies had antepartum hemorrhage. This similar observation was established by Khannaet al ${ }^{16} 1984$.

\section{Conclusion}

Congenital malformation constitute 8.1/1000 births and accounts for important cause of mortality and morbidity in neonatal period. Our ultimate goal is to gain insight into etiology and focus on elimination, modification or control of teratogens in the environment. In an effort to analyse the causative factors of congenital malformations it is found that in majority of patients, the cause is obscure. Improvement of literacy and socioeconomic status of the community and proper antenatal care is a very important aspect. As far as possible restriction of medications during early pregnancy should be done. In case of elderly mothers and in those with previous history of abortions, still birth or malformed baby, the mother should undergo serial ultrasonography orbiochemical screening for early detection of any malformation. Medical termination of uncontrollable severe malformation will partially reduce the incidence of congenital malformation. The life threatening congenital malformation must be identified by thorough clinical examination and other investigations because early detection and surgical correction of these infants offer the best chance of survival.

\section{References}

[1]. WHO Sixty-Third World Health Assembly Provisional Agenda Item 11.7 report by Secretariat on Birth Defects: 1April 2010.A63/10

[2]. John P. Cloherty. Manual of Neonatal Care: $7^{\text {th }}$ Edition. Philadelphia: Lippincott Williams \& Wilkins;2012

[3]. Bari MFC. Spectrum of Congenital Anomalies Among Children Attending the Pediatric Departments of Dhaka Medical College Hospital. IOSR Journal of Dental and Medical Sciences.Feb2014:13:20-21.

[4]. Swain S, Aggarwal A, Bhatia BD. Congenital Malformations at Birth. Indian Pediatrics.Oct1994;31:1187

[5]. Bhat BV, Babu L. Congenital Malformation at Birth-a Prospective Study from South India. Indian J Pediatr.1998 Nov-Dec:65:87381.

[6]. Datta V, Chaturvedi P. Indian Pediatrics.2000:37:998-1001.

[7]. Bhide $\mathrm{P}$ etal. Systematic review of Birth prevalence of Neural Tube Defects in India. Birth Defect Res A ClinMol Teratol.2013;97(7):437-43

[8]. Shah K, Pensi CA. Study of Incidence of Congenital Anomalies in Newborns. Gujarat Medical Journal. Dec2013; 8:97

[9]. Ghorpade N, Goyal N, John J. Prevalence of musculoskeletal abnormalities in new born: A10 years retrospective analysis of 10,674 neonates in Indian population at a tertiary care hospital . J Clin Neonatal.2015:4:104-108.

[10]. Grover N. Congenital malformations in Shimla. Indian Pediatric.2000 April: 67:249-51.

[11]. Rani S, Lakshmi VAA. Study of Congenital Malformations in a Tertiary Hospital, Guntur. IOSR Journal of Dental and Medical Science (IOSR-JDMS).April2015:14(4):16-20

[12]. Sarkar S. Patra C etal. Prevalence of Congenital Anomalies in Neonates and Associated Risk Factors in a Tertiary Care Hospital in Eastern India. J Clin Neonatal.2013 July-Sep: 2(3);131-134.

[13]. Hatibaruah A, Hussain S.A.M. Study on Prevalence of Birth Defects and its Association with Risk Factors in Fakhrudhin Ali Ahmed Medical College and Hospital. Journal of Evidence Based Medicine and HealthCare.July2015; 2:4336-4343.

[14]. Singh K, Krishnamurthy K e tal. Major Congenital Malformations in Barbados: the Prevalence, the Pattern, and the Resulting Morbidity and Mortality. ISRN Obstetrics and Gynecology. 2014; 651783.

[15]. Smith DW: Recognisable patterns of human malformation: 3ed Philadelphia. WB Saunders Co.1982

[16]. Khanna KK, Prasad LSN: Ind J Pediatr;1967;34:63-67.

Appendix
Table 1
\begin{tabular}{|l|l|l|}
\hline SYSTEM & SYMPTOM & INVESTIGATION \\
\hline Cardiovascular system & $\begin{array}{l}\text { Cyanosis, respiratory distress, } \\
\text { Feeding difficulty, any murmur, arrhythmia }\end{array}$ & $\begin{array}{l}\text { Chest Xray, Echocardiography, } \\
\text { Electrocardiogram. }\end{array}$ \\
\hline Central nervous system & $\begin{array}{l}\text { Abnormal head size, bulging frontanelle, } \\
\text { antenatal USG showing of large head, any spinal } \\
\text { deformity }\end{array}$ & $\begin{array}{l}\text { X ray skull, USG brain and CT } \\
\text { scan }\end{array}$ \\
\hline Respiratory system & $\begin{array}{l}\text { Cyanosis, respiratory distress, Frothing from } \\
\text { mouth }\end{array}$ & $\begin{array}{l}\text { Chest X ray, x ray neck with } \\
\text { rubber tube in situ }\end{array}$ \\
\hline
\end{tabular}


A Study Of Congenital Malformations Amongst Hospital Deliveries, Gauhati Medical College..

\begin{tabular}{|l|l|l|}
\hline Gastrointestinal system & $\begin{array}{l}\text { Unable to pass meconium within 24 } \\
\text { hoursafterbirth,Billiousvomiting,Abdominaldiste } \\
\text { nsion }\end{array}$ & Infantogram \\
\hline Urogenital system & $\begin{array}{l}\text { Unable to pass urine } 48 \text { hrs after birth. } \\
\text { Abdominal mass, antenatal oligohydromnious, } \\
\text { neonatal ascites }\end{array}$ & USG abdomen. \\
\hline
\end{tabular}

Table 2

\begin{tabular}{|l|l|l|}
\hline System involved & Number of cases & \% of total malformation \\
\hline Central Nervous System & 30 & 17.44 \\
\hline Musculoskeletal system & 42 & 24.41 \\
\hline Gastrointestinal system & 22 & 12.79 \\
\hline Orofacial & 14 & 8.14 \\
\hline Genitourinary & 18 & 10.46 \\
\hline Cardiovascular system & 14 & 8.14 \\
\hline Eye & 4 & 2.33 \\
\hline Ear & 6 & 3.48 \\
\hline Syndrome & 10 & \multicolumn{2}{|c|}{5.81} \\
\hline Cutaneous & 12 & 6.97 \\
\hline
\end{tabular}

Figure 1

\section{SYSTEM WISE DISTURBUTION OF \\ CONGENITAL MALFORMATION}

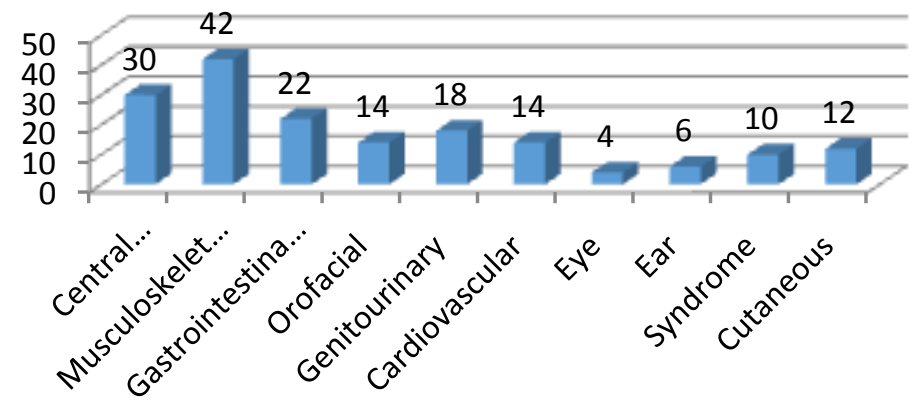

Table 3

\begin{tabular}{|l|l|l|}
\hline \multirow{2}{*}{ ANTENATAL PROBLEMS } & MALFORMATION \\
\cline { 2 - 3 } & NUMBER OF CASES & PERCENTAGE (\%) \\
\hline Fever during $1^{\text {st }}$ Trimester & 16 & 12.30 \\
\hline Rash & 2 & 1.54 \\
\hline PIH & 12 & 9.23 \\
\hline Polyhydramnios & 2 & 1.54 \\
\hline Oligohydramnios & 2 & 1.54 \\
\hline Maternal Diabetes Mellitus & 1 & 0.77 \\
\hline Antepartum haemorrhage & 10 & 7.69 \\
\hline Antenatal Drug/radiation & 0 & \multicolumn{2}{|l}{0.00} \\
\hline Tobacco/ Alcohol & 0 & 0.00 \\
\hline
\end{tabular}

Table 4

\begin{tabular}{|l|l|}
\hline PREVIOUS STUDY & INCIDENCE \\
\hline Swain S et.al & $1.2 \%$ \\
\hline Bhat BVet.al & $3.7 \%$ \\
\hline Datta V et.al & $1.24 \%$ \\
\hline Grover N & $1.78 \%$ \\
\hline Rani S et al & $0.9 \%$ \\
\hline Baruah J et al & $1.13 \%$ \\
\hline Hatibaruah A et al & $0.7 \%$ \\
\hline Present study & $0.81 \%$ \\
\hline
\end{tabular}

